\title{
Visión constitucional del debido proceso en materia inspectiva laboral
}

\author{
Jorge Toyama Miyagusuku \\ Abogado por la Pontificia Universidad Católica del Perú. \\ Máster en Derecho Constitucional por la Pontificia Universidad Católica del Perú. \\ Profesor Principal en la Pontifica Universidad Católica del Perú. \\ Profesor en la Universidad ESAN. \\ Profesor en la Universidad del Pacífico. \\ Vocal del Tribunal de Servicio Civil.

\section{Carole Neyra Salazar} \\ Abogada por la Universidad San Martín de Porres. \\ Cursando la maestría en Derecho de la Empresa de la \\ Pontificia Universidad Católica del Perú. \\ Asistente del curso de Legislación Laboral de la Maestría en \\ Organización y Dirección de Personas de ESAN.
}

SUMARIO:

I. Introducción.

II. Concepto y marco normativo:

1. Concepto;

2. Marco normativo.

III. Contenido constitucionalmente protegido: Derecho al debido proceso.

IV. Debido proceso: Pronunciamientos del Tribunal Constitucional:

1. Manifestaciones del principio del debido proceso:

1.1. Debida motivación;

1.2. El derecho de defensa;

1.3. El derecho al plazo razonable;

1.4. Principio de legalidad o tipicidad;

1.5. Imparcialidad y objetividad;

1.6. Derecho a probar.

V. Reflexiones finales. 


\section{INTRODUCCIÓN}

Desde hace casi cinco años las inspecciones laborales son uno de los instrumentos más importantes para que los trabajadores y sindicatos tutelen sus derechos laborales además porque, salvo la reposición de trabajadores cesados, la fiscalización laboral puede, en un proceso célere, determinar si existe un incumplimiento. Las facultades de los inspectores deben ser ejercidas dentro del marco del debido proceso, y esta es la razón más común mediante la cual las actas de infracción y/o resoluciones emitidas por el Ministerio de Trabajo -en adelante MTPEse declaran nulas las inspecciones de trabajo.

Actualmente la actuación del MTPE en nuestro país, a través de las inspecciones laborales, ha adquirido preeminencia en distintos sectores económicos que, inclusive, ha involucrado a los principales actores de una relación laboral, como son los sindicatos, trabajadores y empleadores al momento de tomar una determinada decisión, en tanto que las actuaciones realizadas por los inspectores de trabajo actualmente están cumpliendo un rol importante en la política del actual gobierno.

En esa misma línea, y de acuerdo a la información publicada por el MTPE, la actuación inspectiva conlleva a que un elevado número de empresas registradas en las planillas electrónicas sean fiscalizadas por dicha institución, más aún si consideramos que dicho mecanismo se ha convertido en la forma más expeditiva para el cumplimiento de muchas obligaciones laborales, y que se coadyuva con la contratación adicional de inspectores de trabajo y por la voluntad política de constituir al proceso inspectivo como un instrumento relevante para lograr el cumplimiento de las obligaciones laborales.

Es por dicha razón que al momento de realizar una fiscalización laboral se pueden presentar actuaciones discrecionales por parte de los inspectores de trabajo que en virtud de las facultades otorgadas por ley se deberán tener en consideración. Si bien es cierto, actualmente ha sido derogada la resolución directoral emitida por el MTPE meses antes referida a los "Criterios Metodológicos para la aplicación del Principio de Primacía de la Realidad", en adelante "Ios criterios", consideramos tener en cuenta su contenido porque en la práctica es muy posible que los inspectores sí lo consideren en las visitas inspectivas.

En ese sentido, las actuaciones del inspector de trabajo llevan impregnadas la presunción de certeza que le otorga la ley, sin perjuicio que adicionalmente deberían encontrarse respaldadas con medios probatorios que coadyuven a determinar la responsabilidad por parte del sujeto inspeccionado, a fin de garantizar y observar la presunción constitucional de inocencia (inherente a todo sujeto de derecho), y, en definitiva, no afectar el principio constitucional del debido proceso.

De esta forma, y según el citado criterio, cuando los hechos son captados directamente por el inspector mediante sus sentidos generan certeza (por ejemplo, una verificación en materia de seguridad y salud en el trabajo); en cambio cuando es necesario apreciar la voluntad de las partes la certeza no puede ser absoluta y, en estos casos, es necesario apreciar las facultades con las que cuenta el inspector. Es imprescindible mencionar que debe realizarse una descripción detallada de los hechos, circunstancias y demás medios probatorios que sustenten los indicios para determinar una posición, de tal manera que no se contravenga algún derecho implícito del debido proceso.

En ese sentido, a través de este artículo, intentaremos conocer cuáles son las distintas manifestaciones del debido proceso, y que han ido evolucionando en el devenir del tiempo, ya sea a través de diversos criterios emitidos por el máximo intérprete de la Constitución, el Tribunal Constitucional o por el MTPE dentro de los procesos inspectivos laborales que se desarrollan en el ámbito administrativo, con

1. Resolución Directoral 096-2011-MTPE/2/16, emitida con fecha 04 de noviembre de 2011, derogada por la Resolución Directoral 012-2012-MTPE/2/16. 
el objeto de estudiar los diversos extremos que configuran el derecho al debido proceso y eviten cualquier tipo de dilaciones en el tiempo que pudiera afectar su derecho como sujetos administrados.

\section{CONCEPTO Y MARCO NORMATIVO}

Anteriormente en nuestro país se tenía una idea restringida en relación al debido proceso, toda vez que hasta mediados del siglo pasado se pensaba que dicho principio sólo correspondía a los procesos jurisdiccionales, sin embargo a la fecha esa percepción ha sido superada, toda vez que la observancia del debido proceso no es de aplicación exclusiva del ámbito jurisdiccional sino que también se ha avocado al ámbito administrativo.

Dicha concepción fue cambiando y hacia 1996 el Tribunal Constitucional refería que "(...) el respeto de las garantías del debido proceso también son de aplicación en cualquier clase de proceso o procedimiento disciplinario privado (...)"2. Adicionalmente, y en el derecho comparado dicha aplicación ha sido desarrollada vertiginosamente en el marco de un proceso judicial (nacional o internacional) como de un procedimiento (administrativo, arbitral o militar) ${ }^{3}$ e, inclusive, se traslada a las relaciones entre particulares cuando existe un procedimiento que observarse.

Ello quiere decir que si bien es cierto el debido proceso es una garantía derivada del ámbito jurisdiccional, no necesariamente se delimita a dicha esfera, debido a que también lo encontramos en el derecho administrativo, en cuya materia se encuentra inmerso el proceso inspectivo laboral, tal como lo veremos a continuación.

\section{Concepto}

El debido proceso es definido como aquel derecho que tiene toda persona de invocar y exigir a un órgano el respeto de un conjunto de principios procesales, para que una controversia pueda resolverse con auténtica justicia.

Desde ese punto de vista, se entiende que el debido proceso -conocido también en la doctrina como proceso justo- es una garantía constitucional y un principio procesal esencial, donde todo justiciable tiene derecho a la defensa, con pleno respecto de las normas, que comprende a un conjunto de principios relativamente heterogéneos, pero absolutamente independientes, que conforman una unidad con relación al tipo de proceso que exige un Estado de Derecho, principios que además han de determinar el curso regular de la administración de justicia por parte de sus operadores y que se instituyen como reglas y formas cuyo fin es la protección de los derechos de las personas ${ }^{4}$.

El principio del debido proceso contiene múltiples expresiones y manifestaciones que se deben observar, por lo que para entenderlo íntegramente es necesario revisar el rol que cumple el término "justicia" dentro de este principio. En ese sentido, debemos decir que la conexión que debe existir entre el debido proceso y la justicia es una concepción derivada de la doctrina norteamericana ${ }^{5}$, mediante la cual se pone de manifiesto que el desarrollo del proceso y la decisión emitida deba ser justa y no arbitraria, es decir dicha manifestación no podrá derivarse de una arbitrariedad por parte del juzgador (entiéndase emitido por un órgano jurisdiccional o administrativo encargado de resolver un conflicto de intereses). $\mathrm{Si}$

2. Expediente No. 067-93 AA/TC-Lima.

3. BUSTAMANTE ALARCÓN, Reynaldo. Una aproximación a la vigencia del debido proceso en los despidos laborales. A propósito de una jurisprudencia del Tribunal Constituciona". En: lus et Veritas No. 21. pp. 301-310.

4. CAS. No. 475-05 Lima, emitida por la La Sala de Derecho Constitucional y Social Transitoria de la Corte Suprema de Justicia de la República de Lima.

5. Con respecto a la doctrina americana, revisar a BUSTAMANTE ALARCÓN, Reynaldo:“Una aproximación...." Ob. Cit., pp. 301-310; "El derecho a una decisión justa como elemento esencial de un proceso justo". En: Revista Derecho \& Sociedad No. 15. pp. 38-51 y “El derecho fundamental a probar y su contenido esencial". En: lus et Veritas No. 14, pp. 171-185. 
hubiera arbitrariedad, debería declararse nula aquella decisión injusta que afecte al debido proceso, que incluye el derecho de defensa, la debida motivación, legalidad, entre otros que veremos seguidamente.

Al respecto, el debido proceso tiene diversas maneras de manifestarse ${ }^{6}$, de las cuales las principales expresiones son:

- Derecho a exponer argumentos: Consiste en el derecho a exponer las razones para las pretensiones y defensa de las partes antes de la emisión de los actos que se refieran a sus intereses y derechos, a interponer recursos y reclamaciones y tener el patrocino de la forma que considere más conveniente a sus intereses.

- Derecho a ofrecer y producir pruebas: Consiste en el derecho a presentar material probatorio, a exigir que la administración produzca y actúe los ofrecidos por el administrado en tiempo hábil, y a contradecir aquellos que la administración considere relevante para resolver el asunto.

- Derecho a obtener una decisión motivada y fundada en derecho: Consiste en el derecho que tienen los administrados para que las decisiones de las autoridades respecto a sus intereses y derechos hagan expresa consideración de los principales argumentos jurídicos y de hecho, así como de las cuestiones propuestas por ellos en tanto hubieren sido pertinentes a la solución del caso.

En definitiva, el debido proceso es una garantía constitucional que permite brindar un adecuado ejercicio del derecho de defensa de los administrados, una debida motivación que contenga la fundamentación jurídica, y que exprese una suficiente justificación de la decisión que se adopte, caso contrario estaríamos ante una resolución arbitraria emitida fuera del ordenamiento legal y que se entendería como una contravención al debido proceso.

\section{Marco normativo}

El debido proceso se encuentra reconocido por el numeral 3) del artículo 139 de la Constitución Política del Perú que una garantía de la administración de justicia es la observancia del debido proceso. Cabe indicar que dicho principio también se encuentra desarrollado dentro del procedimiento administrativo, en la Ley 27444 -Ley del Procedimiento Administrativo General, a través del siguiente articulado:

"Artículo IV, 1.2. del Título Preliminar.Principio del debido procedimiento Los administrados gozan de todos los derechos y garantías inherentes al debido procedimiento administrativo, que comprende el derecho a exponer sus argumentos, a ofrecer y producir pruebas y a obtener una decisión motivada y fundada en derecho (...)".

En ese mismo sentido, la Ley 28806, Ley General de Inspección del Trabajo -en adelante LGIT-, también lo ha reconocido en su artículo 44 al señalar que:

"(...) las partes gozan de todos los derechos y garantías inherentes al procedimiento sancionador, de manera que les permita exponer sus argumentos de defensa, ofrecer pruebas y obtener una decisión por parte de la Autoridad Administrativa de Trabajo debidamente fundada en hechos y derecho".

El contenido de lo descrito, conjuntamente con otros derechos que se encuentran vinculados al debido proceso, se detalla en el siguiente cuadro resumen:

6. MORÓN URBINA, Juan Carlos. "Principios del Procedimiento Administrativo". En: Comentarios a la Nueva Ley de Procedimiento Administrativo General. Gaceta Jurídica, Lima, 2008, p. 35.

7. Constitución Política del Perú.- Artículo 139 numeral 3.- "La observancia del debido proceso y la tutela jurisdiccional." 


\begin{tabular}{|l|l|}
\hline \multicolumn{1}{|c|}{ Materia } & \multicolumn{1}{c|}{ Normativa } \\
\hline Constitucional & $\begin{array}{l}\text { La observancia del debido proceso: Artículo 139, numeral 3) de la Constitución } 1993 \\
\text { Motivación: Artículo 139, numeral 5) de la Constitución 19931 } \\
\text { Derecho de defensa: Artículo 139, numeral 14) de la Constitución 1993² }\end{array}$ \\
\hline Administrativa & $\begin{array}{l}\text { Principio del Debido Procedimiento: Artículo IV, 1.2. del Título Preliminar de la } \text { LPAG }^{3} \\
\text { Motivación: Artículo 3, numeral 3.4) de la LPAG } \\
\text { Motivación del acto administrativo: Artículo 6 de la LPAG }\end{array}$ \\
\hline Laboral & Principios generales del procedimiento: Artículo 44 de la LGIT $^{6}$. \\
\hline
\end{tabular}

1. Constitución Política del Perú.- Artículo 139 numeral 5.- "La motivación escrita de las resoluciones judiciales en todas las instancias, excepto los decretos de mero trámite, con mención expresa de la ley aplicable y de los fundamentos de hecho en que se sustentan".

2. Constitución Política del Perú.- Artículo 139 numeral 14.- "El principio de no ser privado del derecho de defensa en ningún estado del proceso. Toda persona será informada inmediatamente y por escrito de la causa o las razones de su detención. Tiene derecho a comunicarse personalmente con un defensor de su elección y a ser asesorada por éste desde que es citada o detenida por cualquier autoridad".

3. Ley 27444.- Artículo IV, 1.2. del Título Preliminar.- Principio del debido procedimiento.- "Los administrados gozan de todos los derechos y garantías inherentes al debido procedimiento administrativo, que comprende el derecho a exponer sus argumentos, a ofrecer y producir pruebas y a obtener una decisión motivada y fundada en derecho. La institución del debido procedimiento administrativo se rige por los principios del Derecho Administrativo. La regulación propia del Derecho Procesal Civil es aplicable sólo en cuanto sea compatible con el régimen administrativo".

4. Ley 27444.- Artículo 3.4.- Motivación.- "El acto administrativo debe estar debidamente motivado en proporción al contenido y conforme al ordenamiento jurídico".

5. Ley 27444.- Artículo 6.- Motivación del acto administrativo.- 6.1. "La motivación deberá ser expresa, mediante una relación concreta y directa de los hechos probados relevantes del caso específico, y la exposición de las razones jurídicas y normativas que con referencia directa a los anteriores justifican el acto adoptado. 6.2. Puede motivarse mediante la declaración de conformidad con los fundamentos y conclusiones de anteriores dictámenes, decisiones o informes obrantes en el expediente, a condición de que se les identifique de modo certero, y que por esta situación constituyan parte integrante del respectivo acto. 6.3. No son admisibles como motivación, la exposición de fórmulas generales o vacías de fundamentación para el caso concreto o aquellas fórmulas que por su oscuridad, vaguedad, contradicción o insuficiencia no resulten específicamente esclarecedoras para la motivación del acto".

6. Ley 28806.- Artículo 44, literal a).- Principios general del procedimiento.- "El principio sancionador se basa en los siguientes principios: Observación del debido proceso, por el que las partes gozan de todos los derechos y garantías inherentes al procedimiento sancionador, de manera que les permita exponer sus argumentos de defensa, ofrecer pruebas y obtener una decisión por parte de la Autoridad Administrativa de Trabajo debidamente fundada en hechos y en derecho".

\section{CONTENIDO CONSTITUCIONALMENTE PROTEGIDO: DERECHO AL DEBIDO PROCESO}

El contenido constitucionalmente protegido 8 de un derecho se encuentra determinado por aquellos parámetros que delimitan el alcance de los derechos fundamentales, teniendo en consideración que no son absolutos y cuyos límites deberían ser adecuados, necesarios y proporcionados. Para determinar el contenido de un derecho fundamental, como dice
INDACOCHEA", este "contenido no puede ser establecido a priori, sino solo luego de efectuar un ejercicio de interpretación que considere -entre otras cosas- todos los demás principios jurídicos involucrados, las circunstancias fácticas de cada casa en concreto, y también las reglas de precedencia (...)".

Al respecto, el Tribunal Constitucional, en el Exp. No. 00728-2008-PHC/TC, ha definido el contenido constitucionalmente protegido en estos términos: "Así las cosas, todo ámbito

8. Preferimos referirnos al contenido constitucionalmente protegido antes que "contenido esencial de un derecho" pues la expresión contenido esencial pareciera diferenciar un contenido esencial de otro no esencial de un derecho constitucional, como si se generase una diferenciación de expresiones de un derecho constitucional.

9. INDACOCHEA PREVOST, Úrsula. "El Principio de proporcionalidad como criterio metodológico para evaluar las limitaciones al contenido de los derechos fundamentales". En: Gaceta Constitucional No. 2. Lima, 2008, pp. 27-38. 
constitucionalmente protegido de un derecho fundamental se reconduce en mayor o menor grado a su contenido esencial, pues todo límite al derecho fundamental sólo resulta válido en la medida que el contenido esencial se mantenga incólume. Este Tribunal Constitucional considera que la determinación del contenido esencial de los derechos fundamentales no puede efectuarse a priori, es decir, al margen de los principios, los valores y los demás derechos fundamentales que la Constitución reconoce. Si bien es cierto que la exactitud de aquello que constituye o no el contenido protegido por parte de un derecho fundamental, $y$, más específicamente, el contenido esencial de dicho derecho, sólo puede ser determinado a la luz de cada caso concreto, no menos cierto es que existen determinadas premisas generales que pueden coadyuvar en su ubicación. Para ello, es preciso tener presente la estructura de todo derecho fundamental".

El contenido del debido proceso no es unánime en la doctrina así como tampoco es un derecho limitativo sino por el contrario se encuentra muy enlazado con otros derechos fundamentales. Consideramos que el debido proceso tiene como contenido constitucional el derecho de defensa, el derecho a que las resoluciones se encuentren debidamente motivadas y fundada en derecho, el derecho a ser informado sin demora, el derecho a probar, el derecho a que las decisiones emitidas sean justas y no arbitrarias (objetivas), entre otras; en suma, todo aquello que se relaciona con brindar un procedimiento justo y objetivo a las partes, está contenido o vinculado al debido proceso.

\section{DEBIDO PROCESO: PRONUNCIAMIENTOS DEL TRIBUNAL CONSTITUCIONAL}

Como hemos visto, la observancia de este derecho no sólo es aplicable al proceso judicial sino también al procedimiento administrativo, como lo ha señalado el Tribunal Constitucional -en adelante TC- en reiteradas oportunidades al indicar que el derecho al debido proceso no sólo rige para el ámbito judicial, sino también para el proceso administrativo (inclusive, el debido proceso se extiende a los procedimientos entre particulares), tal como se describe en el Exp. No. 02167-2007-PA/TC:

"El derecho al debido proceso, y los derechos que contiene son invocables, y por tanto, están garantizados, no solo en el seno de un proceso judicial sino también en el ámbito del procedimiento administrativo".

Asimismo, en el fundamento 35 del Exp. No. 6149-2006-PA/TC también se ha señalado lo siguiente:

"El derecho al debido proceso, reconocido en el inciso 3) del artículo $139^{\circ}$ de la Constitución, es un derecho cuyo ámbito de irradiación no abarca exclusivamente el campo judicial, sino que se proyecta con las exigencias de su respeto y protección, sobre todo órgano, público o privado".

Entonces, es claro que el debido proceso también abarca al ámbito del procedimiento administrativo, el cual tiene como principal finalidad asegurar los derechos fundamentales consagrados en la Constitución Política del Estado, y garantizar a los administrados una solución acorde a la Constitución.

\section{Manifestaciones del principio del debido proceso}

Las manifestaciones del debido proceso son aquellas expresiones jurídicas que lo conforman, las mismas que han sido plasmadas en distintas resoluciones del TC y del propio MTPE en varias resoluciones. En ese sentido, a continuación comentaremos los principales derechos que lo conforman y que han sido consignados en algunas resoluciones emitidas por dichas instituciones.

\subsection{Debida motivación}

La debida motivación se encuentra referida a que todas las resoluciones emitidas por cualquier autoridad pública deben encontrarse clara y debidamente fundamentadas en las decisiones que se adopten. 
En ese sentido, el TC, mediante Exp. No. 007282008-PHC/TC, ha precisado que el contenido constitucionalmente garantizado de este derecho busca que, entre otros, no se presenten los siguientes supuestos:

A) Inexistencia de motivación o motivación aparente: La contravención del derecho a una decisión debidamente motivada se presenta cuando la motivación es inexistente o cuando la misma es solo aparente.

B) Falta de motivación interna del razonamiento: La falta de motivación interna del razonamiento se presenta en una doble dimensión: por un lado, cuando existe invalidez de una inferencia a partir de las premisas que se establecen previamente a la decisión y, por otro lado, cuando existe incoherencia narrativa, que a la postre se presenta como un discurso absolutamente confuso e incapaz de transmitir, de modo coherente, las razones en las que se apoya la decisión.

C) La motivación insuficiente: Se refiere, básicamente, al mínimo de motivación exigible atendiendo a las razones de hecho o de derecho indispensables para asumir que la decisión está debidamente motivada.

D) La motivación sustancialmente incongruente: Obliga a resolver las pretensiones de las partes de manera congruente con los términos en que vengan planteadas, sin cometer, por lo tanto, desviaciones que supongan una modificación o alteración.

EI TC en reiteradas oportunidades se ha pronunciado respecto al derecho de motivación en los procedimientos administrativos, y así lo ha dispuesto en las siguientes resoluciones:

Exp. No. 08495-2006-AA/TC:"(...) motivar una decisión no sólo significa expresar únicamente al amparo de qué norma legal se expide el acto administrativo, sino, fundamentalmente, exponer en forma sucinta -pero suficiente- las razones de hecho y el sustento jurídico que justifican la decisión tomada".

Exp. No. 4289-2004-AA/TC: "La motivación de una decisión de la Administración no sólo implica expresar la norma legal en la que se ampara, sino fundamentalmente en la exposición suficiente de las razones de hecho y el sustento jurídico que justifican la decisión tomada".

Exp. No. 2192-2004-AA/TC: “(...) dichas resoluciones deban contar con suficiente motivación tanto de los hechos como de la interpretación y/o razonamiento de las normas invocadas por la Administración".

Como puede apreciarse, el máximo intérprete de la Constitución se ha pronunciado y ratificado constantemente sobre la vigencia del debido proceso, cuya aplicación es extendida al procedimiento administrativo.

De esta forma, la motivación contiene tanto el aspecto fáctico como el jurídico del proceso, debiendo además cumplir con aquellas exigencias necesarias, tales como ser expresa, clara, legítima, completa y lógica. La motivación es la manera de justificar la calificación jurídica, por lo que el juzgador se encuentra obligado a fundamentar aquellas consecuencias jurídicas que deriven de la adecuación del hecho en determinada norma.

Tal como lo indica Bustamante 10 "Lo que se busca es que las decisiones que se emitan en un proceso o procedimiento sean adecuadamente motivadas y que no sea una decisión de una mera subjetividad del juzgador, sino una derivación razonada de los valores, normas y circunstancias en torno al cual se desarrolla al caso concreto, así como de las circunstancias comprobadas de la causa".

En ese sentido, la motivación que se expresa en una decisión deberá ser acorde a los principios

10. BUSTAMANTE ALARCÓN, Reynaldo. "El derecho a una decisión justa...." Op. Cit., pp. 38-51. 
racionales para justificar la solución de cada caso en particular; caso contrario se contravendría el principio de un debido proceso justo, afectando de tal manera el ordenamiento jurídico.

\subsection{El derecho de defensa}

El derecho de defensa se encuentra explícitamente inmerso en el principio del debido proceso, el mismo que está regulado en el numeral 14), artículo 139 de la Constitución Política del Perú.

A continuación describimos una resolución emitida por el TC en relación al derecho de defensa, y que también es aplicable al procedimiento administrativo:

Exp. No. 02728-2007-PA/TC: “El derecho de defensa establece una prohibición de estado de indefensión de la persona frente a un proceso o procedimiento que afecte un derecho o interés del mismo. Este derecho no se satisface con el mero y aparente cumplimiento de una ritualidad de noticiar a la persona sobre la existencia de un proceso, sino con el desarrollo de todas las diligencias idóneas a efectos de una comunicación válida y oportuna sobre la existencia de un proceso".

Con respecto al derecho de defensa, veamos un caso en particular. En un proceso inspectivo el inspector de trabajo -mediante requerimiento- solicita al sujeto inspeccionado se abstenga de realizar actos de hostilización contra sus trabajadores sindicalizados, en tanto que ello constituye un perjuicio de la actividad sindical, indicándole a la empresa que se abstenga de ejercer acciones de promoción a la desafiliación de la organización sindical.

De lo expresado, se advierte que no se precisa en qué consiste la acción específica que debe observar el sujeto inspeccionado para cumplir con lo señalado en dicha medida ni tampoco se indica cuáles serían los hechos específicos que serían actos de hostilización y de promoción a la desafiliación de la organización sindical cometidos por parte del sujeto inspeccionado lo cual evidencia una significativa vulneración del derecho de defensa, tal como se establece en la Resolución Sub Directoral 272-2010-MTPE que indica lo siguiente:

"(...) el inspector de trabajo comisionado expidió la medida inspectiva de requerimiento con fecha 20 de enero de 2010, sin la debida motivación concreta, esto es, (el motivo y de qué manera el sujeto inspeccionado, deberá de abstenerse de realizar actos de hostilización que constituyan perjuicio de los 95 trabajadores sindicalizados en su actividad sindical, así como promover la desafiliación de la organización sindical), a efectos de que el sujeto inspeccionado garantice el cumplimiento de la medida adoptada; afectando de esta manera el derecho de defensa del sujeto inspeccionado, toda vez que no permite que el sujeto inspeccionado pueda aportar documentación alguna en defensa de sus derecho ${ }_{L}$ contraviniendo de esta manera el derecho de defensa del sujeto inspeccionado, derecho de defensa que también se encuentra establecido en el ámbito del procedimiento administrativo sancionador(...)".

Si bien es cierto la finalidad del presente artículo no es analizar la medida inspectiva de requerimiento, hemos considerado necesario señalar brevemente que el requerimiento constituye un elemento coadyuvante para evaluar la observancia del debido proceso en aquellos casos donde el requerimiento se emita de forma genérica y no precise en qué consiste la afectación u acto que debería realizar el sujeto inspeccionado para dar cumplimiento a las normas socio laborales.

En ese sentido, y como puede apreciarse en la siguiente resolución, si la medida de requerimiento no indica cuáles son los actos que habría cometido la empresa y los que tendría que dejar de ejecutar para dar cumplimiento a las normas socio laborales supuestamente infringidas, estamos ante una innegable afectación al derecho de defensa:

"Que la medida inspectiva de requerimiento es genérica, no se precisa cuales son 
las materias a subsanar ni se enmarca los hechos que constituyen incumplimientos, por lo que no se puede establecer claramente cuáles son las normas socio laborales infraccionadas, por el contrario frente a toda la documentación adjunta y la falta de constatación de hechos en forma objetiva, se puede establecer que no se ha violado norma socio laboral alguna, por tanto corresponde a este despacho declarar la nulidad del acta de infracción"11.

Por citar otro ejemplo, y del análisis de la Resolución Sub Directoral 05-2010-MTPE/2/12.330, se advierte que el acta de infracción no tiene más soporte probatorio que lo plasmado en la denuncia y la manifestación verbal del trabajador, constituyendo una evidente vulneración al derecho de defensa dado que solamente se reproduce la versión del denunciante sin que se aporte algún medio probatorio para acreditar la emisión del acta de infracción. En concreto, la resolución citada menciona lo siguiente:

“(...) Sin embargo del análisis del acta de infracción materia de autos, se advierte que la inspectora de trabajo comisionada no ha precisado mayores hechos constatados que le permitan a este Despacho meritar conforme a ley, basándose sólo en la denuncia y la manifestación verbal, asimismo no precisa fechas de ingreso o periodo a infraccionar, vulnerando el Debido Proceso de conformidad con el artículo $44^{\circ}$ de la Ley 28806 , así como afectar el derecho de defensa del inspeccionado (...)".

Con respecto a la oportunidad de ejercer el derecho de defensa, cabe indicar que su ejercicio no necesariamente tiene que realizarse en una comparecencia, en tanto que también existen otros momentos para presentar cualquier tipo de documentación o información, las cuales podrían darse durante las actuaciones investigadoras y comprobatorias (en este caso, durante el proceso de investigación), tal como se señala a continuación:
“(...) ambas etapas (investigadoras y comprobatorias) se entrelazan como un conjunto de diligencias que tienen por finalidad comprobar si se cumple con las disposiciones vigentes en materia socio laboral"12.

Como puede apreciarse, el no citar a comparecencia a un sujeto inspeccionado no imposibilita que éste pueda presentar las pruebas que, en defensa de sus respectivos derechos e intereses, considere correspondiente. Sólo en aquellos casos donde no se brindara la oportunidad para la presentación de pruebas, se afectaría el debido proceso.

\subsection{El derecho al plazo razonable}

La duración del procedimiento se encuentra estrechamente vinculada al derecho a un plazo razonable para cumplir lo requerido por la administración, por lo tanto al momento de evaluar la razonabilidad del tiempo transcurrido debe tenerse en cuenta la situación de cada caso en particular y la aplicación del test de la razonabilidad del plazo, tal como lo señala el TC en la siguiente resolución:

"Para determinar si existe la vulneración del derecho a un plazo razonable que también afecta los derechos conexos a la libertad, se aplica el test de la razonabilidad del plazo en el que se desarrolla un proceso que utiliza la Corte Interamericana de Derechos Humanos"13.

Al respecto, una sentencia del Tribunal Europeo de Derechos Humanos ${ }^{14}$ indica que "la duración

11. Resolución 201-2010-GR.CUS/DRTPE.

12. Resolución Directoral 1134-2010-MTPE.

13. Exp. No. 5291-2005-PHC/TC.

14. Tribunal Europeo de Derechos Humanos, sección 2, sentencia del 24 de noviembre de 2009. Recurso. 29908/2005. 
del procedimiento debe evaluarse a la luz de las circunstancias del caso y con referencia a los siguientes criterios: la complejidad del caso, el comportamiento del demandante y las autoridades competentes".

El TC también se ha manifestado sobre los criterios que se deben considerar al momento de evaluar la razonabilidad del tiempo transcurrido dentro de un proceso, señalando que:

"El carácter razonable de la duración de un proceso se debe apreciar según las circunstancias de cada caso y teniendo en cuenta: a) la complejidad del asunto; b) el comportamiento del recurrente; $c$ ) la forma en que el asunto ha sido llevado por las autoridades administrativas (es decir, lo que ordinariamente se demora en resolver determinado tipo de procesos), y d) las consecuencias que la demora produce en las partes"15.

No obstante lo señalado precedentemente, el numeral 6.5. del Lineamiento 013-2008 -en adelante el lineamiento- emitido por el MTPE, hace referencia a los criterios que no generan la nulidad de las actas de infracción, indicando que la falta de notificación del plazo del vencimiento del proceso de investigación o para el proceso administrativo sancionador en primera y segunda instancia- no genera la nulidad del procedimiento, y lo señala de la siguiente manera:

"La falta de notificación oportuna de algún acto dentro del procedimiento inspectivo, no deben ser consideradas sustantivas dentro del procedimiento de investigación, razón por la cual no corresponde decretar una nulidad de las actuaciones inspectivas (...). El mismo criterio debe aplicarse para los plazos de vencimiento del procedimiento de investigación, así como para el procedimiento administrativo sancionador en primera y segunda instancia, el cual no debe generar que se declare nulo el procedimiento en la medida que se haya excedido del plazo establecido por ley".
En ese sentido y teniendo en consideración el mencionado lineamiento, cabe indicar que en aquellos casos que se advierta el vencimiento del plazo para cumplir un acto a cargo del MTPE no generará ningún acto de nulidad, sin perjuicio de las responsabilidades y consecuentes sanciones administrativas que se pudieran imponer a aquel funcionario o responsable que haya ocasionado dicha demora.

\subsection{Principio de legalidad o tipicidad}

El principio de legalidad -o también conocido como tipicidad- es uno de los principios ordenadores del sistema de inspección del trabajo y de la potestad sancionadora administrativa, cuya aplicación es de cumplimiento obligatorio en la actuación de todos los funcionarios y sujetos inspeccionados dentro del sistema inspectivo, según lo dispuesto en la Constitución Política del Perú, las leyes, reglamentos y demás normas vigentes. En ese sentido, una de las vertientes del principio general del debido proceso es el principio de legalidad, según el cual las partes gozan de todas las garantías inherentes al procedimiento sancionador.

Por otro lado y atendiendo a la inobservancia de los requisitos mínimos que debe contener el acta de infracción, cabe indicar que la omisión de aquellos preceptos normativos no indicados podría derivar a una nulidad, por más que se hubiera realizado una descripción detallada de aquellos hechos que originaron el incumplimiento de la normativa socio laboral.

Cabe resaltar que el TC también se ha referido a dicho principio al prohibir una sanción en caso no haya sido determinada por la ley, tal como se señala a continuación:

"El principio de legalidad en materia sancionatoria impide que se pueda atribuir la comisión de una falta si ésta no está previamente determinada en la ley, y también prohíbe que se pueda aplicar

15. Exp. No. 3778-2004-AA/TC. 
una sanción si ésta no está también determinada por la ley"16.

\subsection{Imparcialidad y objetividad}

La imparcialidad y objetividad se presenta como un derecho fundamental a la justicia a través del procedimiento. Se trata de un derecho de carácter instrumental que se encuentra conformado por un conjunto de derechos esenciales que cumplen la función de evitar la arbitrariedad de la administración en perjuicio de los administrados, inclusive ante la ausencia o insuficiencia de un proceso o de un procedimiento ${ }^{17}$.

Al respecto, como ejemplo en la siguiente resolución emitida por el MTPE, se advierte la vulneración del principio de imparcialidad y objetividad al existir un vínculo de consanguinidad entre el inspector de trabajo y uno de los trabajadores involucrados en el proceso. En dicha resolución se evidencia una contravención al artículo 88 de la LPAG y del inciso a) del artículo 28 de la LGIT, el mismo que señala que los inspectores de trabajo no deberán tener interés directo ni indirecto en la empresa o grupo de empresas objeto de su actuación, conforme se indica seguidamente:

"Que, en efecto, en el presente caso el inspector de trabajo (...), es primo hermano de uno de los denunciantes, (...) encontrándose dentro de las causales que prescribe el artículo $88^{\circ}$ de la Ley de Procedimiento Administrativo General, Ley $N^{\circ} 27444$, causal que conlleva a una falta administrativa. (...) Que, de todo lo expuesto se llega a colegir que se ha desnaturalizado y presentado irregularidades que acarrean nulidad insalvable, la misma que debe ser declarada, existiendo desnaturalización e irregularidades en cuando a la forma del procedimiento, más no en el fondo del asunto"18.

\subsection{Derecho a probar}

El derecho a probar es una manifestación del debido proceso, inherente a todo sujeto, el cual se exterioriza mediante la presentación de aquellos medios probatorios dentro de un proceso o procedimiento, el mismo que tiene por finalidad su admisión y actuación -en virtud de los principios que le otorga el ordenamiento jurídico-, sin perjuicio del convencimiento que pueda producir en la autoridad laboral.

Al respecto, el TC también se ha pronunciado en relación a este derecho, mediante su Resolución 6712-2005-HC/TC, manifestando que:

"El derecho constitucional a probar, aunque no es autónomo, se encuentra directamente al derecho al debido proceso. Se constituye un derecho básico de los justiciables de producir la prueba relacionada con los hechos que configuran su pretensión o su defensa. Según este derecho, las partes o un tercero legitimado en un proceso o procedimiento, tienen el derecho a producir la prueba necesaria con la finalidad de acreditar los hechos que configuran su pretensión o defensa".

Por otro lado, el derecho a probar tiene como contenido esencial el derecho a que se admitan, actúen y valoren debidamente los medios probatorios ofrecidos ${ }^{19}$. En ese sentido, si nos trasladamos al proceso inspectivo, tendríamos que decir que el derecho de probar incluye la admisión de medios probatorios, el cual tiene por objeto que se admita los medios ofrecidos por el sujeto inspeccionado, derecho a que se actúen y a que se valoren de forma conjunta,

16. Exp. No. 08957-2006-PA/TC.

17. FAUNDEZ LEDEZMA, Héctor. "El derecho a un juicio justo". En: Las garantías del debido proceso. Instituto de Estudios Internacionales de la Pontificia Universidad Católica del Perú y Embajada Real de los Países Bajos. Lima, 1996, p. 17.

18. Resolución Directoral Regional 051-2009-GR-CAJ-DRTPW.

19. BUSTAMANTE ALARCÓN, Reynaldo. "El derecho fundamental...." Op. Cit., pp. 171-185. 
porque de lo contrario se generaría la afectación del debido proceso del procedimiento inspectivo.

\section{REFLEXIONES FINALES}

Seguidamente detallamos algunas reflexiones finales, a título de conclusiones, sobre la base de lo que hemos abordado en este artículo.

La función que tiene el Ministerio de Trabajo es harto relevante en un país donde la informalidad es la regla y lamentablemente el incumplimiento de las normas suele ser común. En este contexto, el debido proceso brinda una garantía para el desarrollo de la actividad inspectiva tanto para garantizar la actuación imparcial del Estado como para respetar los derechos fundamentales del sujeto inspeccionado.

1. Entre las manifestaciones que se encuentran contenidas en el debido proceso encontramos al derecho de defensa, el cual busca proteger al sujeto inspeccionado frente a una posible indefensión dentro de un proceso, otorgándole todos los instrumentos necesarios para su protección; la observancia del principio de legalidad, a través del cual no se puede atribuir ninguna comisión de falta si ésta no se encuentra previamente tipificada por ley, la misma que la encontramos muy vinculada al principio de imparcialidad y objetividad que impide que cualquier autoridad pública actúe de forma arbitraria y/o discrecional.

2. Asimismo, y con el objetivo que el sujeto inspeccionado pueda ejercer su derecho de defensa la ley le ha otorgado el derecho a probar y refutar cualquier manifestación que se considere que no se ajusta a la realidad, y que se concreta en la presentación, admisión y actuación de los medios probatorios dentro de un proceso, los mismos que tendrían que ser considerados en la evaluación que deben realizar las autoridades al momento de emitir un acta de infracción o una resolución.

3. Las manifestaciones del debido proceso son determinantes para la actuación inspectiva, consideramos que son elementos que deberían tenerse en consideración a fin de evitar cualquier tipo de dilaciones que pudieran presentarse dentro del proceso administrativo para los sujetos que participan dentro del indicado proceso. 